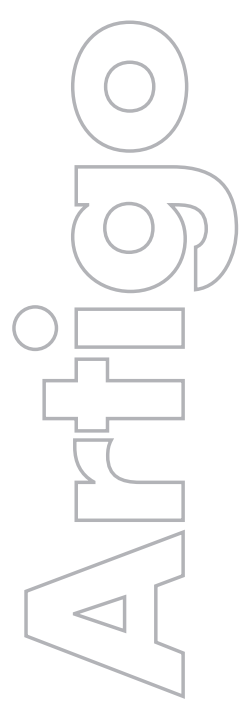

revista

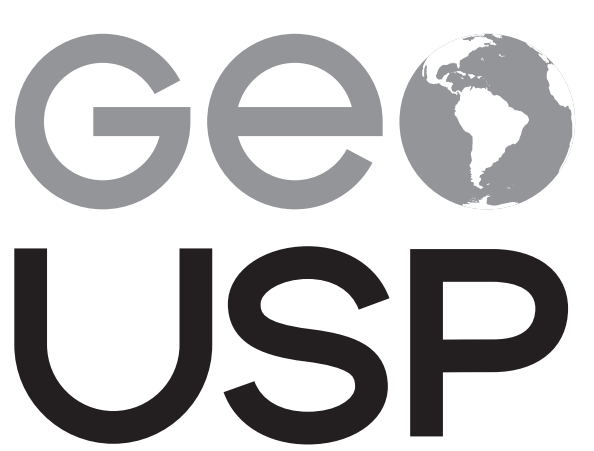

espaço e tempo

Volume $22 \cdot n^{\circ} 2(2018)$

ISSN 2179-0892
Relações de gênero e

a Revista Brasileira de

Geografia: expressões da

tradição geográfica nacional

(1939-2005)

Tamires Regina Aguiar de Oliveira Cesar UEPG

Vagner André Morais Pinto

UEPG

p. $366-379$

Como citar este artigo:

CESAR, T. R. A. O.; PINTO, V. A. M. Relações de gênero e a Revista Brasileira de Geografia: expressões da tradição geográfica nacional (1939-2005). Geousp - Espaço e Tempo (Online), v. 22, n. 2, p. 366-379, mês. 2018. ISSN 2179-0892.

Disponível em: http://www.revistas.usp.br/geousp/article/ view/134425. doi: http://dx.doi.org/10.11606/issn.2179-0892. geousp.2018.134425.

\section{(c) $(1) \Theta$}

Este artigo está licenciado sob a Creative Commons Attribution 4.0 License. 


\title{
Relações de gênero e a Revista Brasileira de Geografia: expressões da tradição geográfica nacional (1939-2005)
}

\section{Resumo}

$\bigcirc$ artigo pretende ressaltar as implicações das relações de gênero no contexto científico geográfico brasileiro a partir da tradicionalíssima Revista Brasileira de Geografia (RBG). Adota-se uma perspectiva epistemológica pautada na ciência como um campo de poder instituído por regulamentações, hierarquias e tensionamentos. $\bigcirc$ universo de dados consistiu em 723 artigos publicados em 222 edições disponíveis on-line do periódico no período 1939-2005. Variáveis desses artigos (título, ano, nome do[s] autor[es], sexo e procedência institucional, entre outras) foram armazenadas em um banco de dados do pacote LibreOffice. Os dados evidenciam a tardia e relativamente baixa representatividade das mulheres em termos de publicações naquela que foi a principal estante da Geografia Brasileira.

Palavras-chave: Produção científica. Gênero. Revista Brasileira de Geografia. Epistemologia. Tradição.

\section{Gender relations and the Revista Brasileira de Geografia: expressions from national geographical tradition (1939-2005)}

\begin{abstract}
The aim of this article is to emphasize the implications of gender relations in the Brazilian geographical scientific context, based on the traditional Revista Brasileira de Geografia (RBG). Was adopted an epistemological perspective based on science as a field of power instituted under regulations, hierarchies, and tensions. The universe of data analyzed consisted of 723 articles published in 222 issues available online on the periodical, during the period 1939-2005. Variables of these articles (article title, year, author's name, gender, institutional origin, among others) were stored in a database by LibreOffice package. The data show the tardy and relatively low representation of women in terms of publications in what was the main bookcase of the Brazilian Geography.
\end{abstract}

Keywords: Scientific production. Gender. Revista Brasileira de Geografia. Epistemology. Tradition. 


\section{Introdução}

No presente texto, temos o objetivo de evidenciar as implicações das relações de gênero no campo científico geográfico a partir da célebre Revista Brasileira de Geografia (RBG). Em princípio, a ciência é aqui compreendida como um campo de poder hegemônico e hierárquico que privilegia determinados grupos e invisibiliza grupos minoritários. As relações de poder são compreendidas de forma não oposicional, mas em feixes de tensionamentos, como se verá na sequência. As estruturas de poder que hierarquizam a sociedade também estão presentes no campo científico como é o caso do gênero. Mesmo com a participação ativa das mulheres no mundo científico, as mesmas ainda estão em desvantagens e por vezes invisibilizadas dessa produção do conhecimento.

Num primeiro momento, discutimos a ciência, sobretudo a Geografia, de uma perspectiva espacial e sociológica, e também esclarecemos o movimento epistemológico que colocou o gênero no centro das discussões da produção do saber científico. Na sequência, resgatamos a importância e o pioneirismo da RBG na divulgação dos trabalhos científicos realizados no país, da qual nos valemos para estabelecer um levantamento da produção de artigos entre homens e mulheres no transcurso das várias décadas de funcionamento desse periódico exemplar.

\section{As implicações entre o fazer científico geográfico e as relações de gênero}

Como uma forma de compreender o mundo, a ciência foi praticada de modo hegemônico, suplantando várias outras formas de conhecimento como o senso comum e a visão teológica. A consideração de sua superioridade e legitimação social é parte integrante da sociedade ocidental capitalista e um de seus pilares mais fortes. Sendo praticada, predominantemente, por homens brancos, abastados, favoreceu a hierarquização da produção do conhecimento científico, sendo que outros grupos sociais como mulheres e negros, não poderiam protagonizar essa forma "elevada" de conhecimento.

$\bigcirc$ desenvolvimento do conhecimento da perspectiva moderna teve início em meados do século XVI e se estendeu até o XIX. Contudo, pode-se dizer que até os dias atuais ocupa um papel de grande importância na organização da sociedade contemporânea. Segundo Sousa Santos, Meneses e Arriscado (2005), o desenvolvimento da ciência não obedeceu uma simples lógica linear evolutiva, mas que seu processo de conquista de poder e legitimidade social é resultado de complexas relações econômicas e políticas. Ainda para os autores, a ciência é uma obra humana, repleta de interesses e subjetividades, embora se tenha criado uma farsa de objetividade e neutralidade na produção do conhecimento do mundo.

A objetividade seria o primeiro elemento da verdade, pois assim validaria as teorias científicas, podendo considerar simultaneamente o mais recente produto de um consenso sociocultural e histórico da comunidade e da sociedade científica (Morin, 1996). A sociedade científica estrutura-se por determinadas organizações sociais que estão vinculadas a bases econômicas. Notoriamente, a comunidade científica não é um grupo "neutro e desinteressado" que, por muitas vezes aparenta ser. Como visto em Fourez (1995), a produção intelectual dos cientistas sempre será influenciada por seu lugar social de origem. Ademais, Morin (1996) também argumenta que, além de não ser neutra, a ciência é intrinsecamente histórica, sociológica e eticamente complexa. 
Compreende-se que a ciência é um campo de poder como argumenta Foucault (1988), desta maneira a ciência geográfica também não deixa de ser um campo de poder que constrói invisibilidades e hegemonias privilegiando alguns grupos, tendo como principal característica o sexo e a raça. Essas características causaram, e ainda causam, grandes dificuldades para que grupos minoritários conseguissem expressar suas espacialidades e que as(os) geógrafas(os) formulassem questões de pesquisas que pudessem construir a visibilidade de grupos que eram deixados de lado pela Geografia, como mulheres, crianças, pessoas negras, e todos os outros que não se enquadram na norma heterossexual dominante, estavam excluídos da produção do saber.

As ausências identificadas no discurso geográfico podem ser entendidas pela legitimidade naturalizada que é encontrada nos discursos hegemônicos de uma Geografia branca, masculina e heterossexual. Essa ciência hegemônica por vezes nega ou invisibiliza a diversidade dos saberes que compõem as sociedades nas mais diversas espacialidades (Silva, 2009).

A ciência geográfica consegue se relacionar com diversos outros conhecimentos; sendo ligada às realidades sociais, também se enquadrou como uma ciência de exclusão dos grupos minoritários. Assim, as relações de gênero são um dos temas invisibilizados pela ciência geográfica, que ainda mantém a exclusão de estudos relativos ao tema:

Se não conhecermos os papéis a serem desempenhados por cada um dos gêneros no estudo da sociedade, não se pode apresentar uma análise razoável das espacialidades e comportamento das mulheres e dos homens, nem das instituições que se alimentam destes comportamentos como também os influenciam (André, 1990, p. 335).

As reflexões da autora são resultantes da influência de intelectuais que décadas antes começam a criticar a ciência geográfica e o sistema hierárquico nela predominante. As discussões sobre gênero emergem na Geografia a partir da década de 1960, com o início da segunda onda do movimento feminista que buscava dar ênfase aos grupos invisibilizados pelas ciências. Para Silva (2009), a Geografia é uma ciência em que o saber se desenvolve diante de um contexto histórico-geográfico. Entre os vários movimentos da década de 1960, o feminista foi de extrema importância para inspirar geógrafas a iniciarem um movimento na década seguinte e reivindicar a construção da igualdade entre homens e mulheres.

Segundo Narvaz e Koller (2006), o feminismo seria um movimento político e filosófico com a proposição de reconhecer as diferenças das experiências entre o universo masculino e feminino, expondo, assim, a necessidade de que pessoas diferentes sejam tratadas não como iguais, mas com a mesma equivalência. As feministas estadunidenses reivindicavam a igualdade entre gêneros, em paralelo a este acontecimento as francesas apontavam a necessidade da valorização das diferenças entre homens e mulheres, especificamente as experiências femininas.

Segundo as autoras, a primeira geração (ou a chamada primeira onda do feminismo) é o marco do nascimento do movimento feminista, que surgiu com um movimento liberal de luta das mulheres pela igualdade em direitos civis, educativos e políticos. $\bigcirc$ foco do movimento feminista era a luta contra a discriminação das mulheres e a segurança dos direitos garantidos, sendo um deles ao voto. 
A segunda onda do movimento desponta nas décadas de 1960 e 70, destacando-se as manifestações na França e nos EUA. Dessa vez, as reivindicações das estadunidenses eram acerca da opressão masculina e a busca pela igualdade, enquanto as francesas apontavam o quanto era necessário valorizar as diferenças encontradas entre os universos feminino e masculino.

Como visto anteriormente, a década de 1960 foi marcada pela reivindicação de discussões de gênero, e não foi diferente na ciência geográfica. Esse debate foi travado primeiramente por geógrafas inglesas e estadunidenses, quando essas contextualizavam as novas discussões referentes ao tema de gênero com o objetivo de construir uma igualdade entre homens e mulheres no âmbito da disciplina. Os questionamentos dessas mulheres desafiavam as filosofias, os conceitos e as metodologias que permeavam a hegemonia de uma Geografia androcêntrica; esse momento na história da ciência geográfica enquadra-se na primeira onda do movimento feminista.

Entretanto, nos anos 1980 e 90, o movimento feminista parte para sua terceira onda questionadora, agora protagonizada por mulheres negras de países do terceiro mundo, que, como aponta Silva (2009), sentiam-se prejudicadas como representatividade dentro da Geografia Feminista, pois o contexto em que a ciência geográfica se configurava era feito de um olhar branco/heterossexual.

Diante dessas novas críticas, abriu-se um caminho para um desenvolvimento epistemológico no campo da Geografia Feminista, pois o movimento deveria repensar essas invisibilidades ainda presentes como a questão da etnia, raça e a sexualidade Mesmo depois dos questionamentos levantados pelo movimento feminista as mulheres ainda permanecem com menor visibilidade em diversos campos sendo eles sociais ou profissionais.

Diversos estudos foram realizados em torno do aumento da presença feminina no campo acadêmico e científico na ciência geográfica. Para comprovar essa invisibilidade feminina nos estudos geográficos as reflexões de McDowell e Peake (1990), apresentam que por mais de uma década de esforços das geógrafas feministas, os postos mais altos das hierarquizações de poder ainda eram ocupados por homens. Indo um pouco mais além, as reflexões das autoras ainda constatam que, mesmo com o ingresso das mulheres nos cursos de Geografia, a representação feminina era menor em cargos de alto grau acadêmico.

Essa menção à invisibilidade das mulheres em âmbito acadêmico foi destacada por Monk e Hanson (1982), no conhecido artigo "On not excluding half of the human in Human Geography". As pesquisadoras se preocupavam com a distinção entre homens e mulheres nas academias universitárias e como essa falta de atenção ao tema era explícita ou implícita no campo da Geografia Humana.

Em reflexões sobre as relações de gênero, García-Ramón, Ortiz e Pujol (2011) discutem as condições de produção científica das mulheres nas universidades espanholas. As autoras argumentam que há diferenças fundamentais entre os universos feminino e masculino que implicam mais vantagens aos homens na organização acadêmica universitária, já que as mulheres desempenham dupla jornada de trabalho, considerando suas funções como mães e donas de casa. Esse resultado da pesquisa da autora indica a hierarquização e dominância do discurso heterossexual masculino.

Investigação similar foi conduzida por Silva, Cesar e Pinto (2015) na Universidade Estadual de Ponta Grossa (UEPG). Aplicaram-se questionários sobre o uso do tempo a seis casais heterossexuais de docentes pesquisadores de diversas áreas, sob idênticas condições de trabalho. Os resultados apontaram disparidades na organização e no dispêndio de tempo nas diversas ati- 
vidades cotidianas entre mulheres e homens. A fim de não prejudicar as atividades acadêmicas e de reprodução familiar, as mulheres tinham seu tempo de repouso reduzido, mas o mesmo não acontecia com os homens, que gastavam menos tempo nessas atividades, sobretudo em fins de semana, obtendo, assim, mais tempo para suas atividades universitárias. A mesma pesquisa aferiu que a presença de filhos se configurou como um agravante dessa discrepância de uso do tempo entre homens e mulheres, restringindo significativamente o desempenho acadêmico destas.

Do mesmo modo, Rose (1993), McDowell (1999), Silva (2009) e Silva, Cesar e Pinto (2015) mostram que existem dualidades oposicionais presentes no pensamento científico que organizou o universo feminino e masculino. Ainda Rose (1993) e McDowell (1999) fazem uma crítica às práticas geográficas que têm alimentado a estrutura dual hierarquizada, privilegiando as características masculinas em detrimento das femininas.

As reflexões de García-Ramon, Ortiz e Pujol (2011) exploram as produções científicas realizadas por geógrafas no contexto das universidades espanholas. Em um dos campos exploratórios das autoras, os dados apontam uma menor publicação feminina, conduzindo à ideia de que a dupla jornada feminina de trabalho está relacionada a esse resultado.

Esses dados indicam que a maioria das mulheres que participam do corpo docente das universidades espanholas são divorciadas, com filhos adultos e viúvas ou solteiras. Segundo García-Ramón (1988), existem estratégias femininas que devem ser levadas em conta por causa da dupla jornada de trabalho a qual representa o campo familiar e profissional.

As discussões de Rose (1993) indicam que as mulheres geógrafas devem assumir referenciais masculinos de ciência, sendo que o discurso geográfico é visto como construído pelo homem branco, burguês e heterossexual, induzindo a hegemonia de suas concepções sobre gênero, raça e sexualidades. Ainda para a autora, a feminilidade é entendida por suas distinções relativas à masculinidade, às identidades raciais e sexuais que são criadas pelo autor com a percepção de um sujeito branco e heterossexual.

Reflexões consonantes são as de Ribeiro (2011), que discute o mito da fragilidade feminina e como está enraizada no coletivo do mundo ocidental a ideia de que o homem seja dotado de razão e a mulher, de sensibilidade.

Nesse sentido, essas ponderações podem ser reforçadas pelas críticas de McDowell (1999), que afirma que essa relação está ligada ao espaço e com a definição do que é "natural" e do que é "cultural", então, é relativa às regulamentações que influenciam quem ocupa determinado espaço e está sendo excluído por ele. Isso se reflete na estruturação do pensamento geográfico e em sua produção científica.

Ainda para McDowell (1999), há uma lista de distinções binárias desse discurso geográfico generificado, um discurso familiar ao senso comum, sendo entendida como ordem "natural" da organização da realidade e assim produz um discurso "neutro" diante do que diz respeito a produção das desigualdades sociais. Logo o pensamento binário acaba por refletir em uma produção hierárquica que é interiorizada na vida cotidiana, a qual traz consequências nas estruturações de práticas de relações sociais, reverberando assim, nas relações espaciais.

Para Silva (2009), compreender as ausências, silêncios e invisibilidades do discurso científico é poder reconhecer que essas características não são fruto do mero acaso e sim de determinada forma de conceber e de fazer Geografia. Deste modo, perspectivas teórico-analíticas que tragam inteligibilidade para fenômenos invisibilizados são fundamentais para a emergência de debates salutares e plurais neste campo. 


\section{A RBG e o início da produção científica geográfica brasileira (1939-2005)}

Conforme discutido na seção anterior, as relações de gênero compõem o campo cientifico desde a institucionalização deste saber. $\bigcirc$ sistemático afastamento e subalternização das mulheres dos contextos acadêmicos atravessou os séculos e ainda persiste na contemporaneidade, mesmo com o maior acesso das mulheres às universidades. Um dos produtos materiais da atividade acadêmica é a produção de artigos científicos, os quais expressam proposições teóricas que forjam poder simbólico pela legitimação das teorias.

A produção do conhecimento científico segue uma norma estabelecida que molda o tabuleiro científico da Geografia brasileira, mas a produção do conhecimento intelectual existe pela participação dos jogadores. Nesse sentido, o espaço acadêmico pode ser analisado a partir do conceito de campo proposto por Bourdieu (2004), que o entende como um jogo que tem regras a "ser seguidas". Como argumenta o autor, essas regras regulam a distribuição do poder dos agentes e das instituições, podendo ensejar expansão ou limitação do campo.

A partir dessas regras que estabelecem o jogo acadêmico, as publicações científicas mantidas por entidades geográficas, constituem um elemento central na divulgação e nos embates que são inerentes ao campo científico. Assim, legitima-se fortemente o papel masculino na produção do conhecimento cientifico geográfico brasileiro por suas publicações desde o início da institucionalização desse saber no país.

Nesse sentido, a RBG foi uma das mais importantes publicações de artigos da Geografia brasileira. Foi criada em 1939, por meio do Instituto Brasileiro de Geografia e Estatística (IBGE), para divulgar suas pesquisas e atividades, favorecendo o avanço científico geográfico no país (RBG, [s.d.]).

Antes de tudo, torna-se necessário compreender a razão do surgimento da RBG e qual foi sua importância ao longo dos tempos para a ciência geográfica brasileira. Entretanto ao analisar essa revista, há também a necessidade de conhecer a história do órgão que a regia, no caso o IBGE.

Em meados do século XX, no governo Vargas (1930), houve um grande fomento para conhecer melhor o território nacional de um ponto de vista geográfico. $\bigcirc$ então presidente Getúlio Vargas, tinha como ponto central em seus projetos a modernização e conhecimento do território nacional. Assim, em 1934, foi instaurado o Instituto Nacional de Estatística (INE), que só se efetivou em 1936, quando da criação do Conselho Nacional de Estatística (CNE). O objetivo do órgão instaurado era coordenar todas as atividades estatísticas e as esferas administrativas do território nacional (IBGE, [s.d.]).

Assim, criado pelo Decreto-Lei n. 218, de 26 de janeiro de 1938, o INE, mais o Consetho Nacional de Geografia (CNG), passou a ser um só, com o nome de IBGE. Nos primeiros anos de sua sustentação, o Instituto funcionava como autarquia subordinada à Presidência da República, dando à geografia e à estatística ações voltadas para a administração federal. Só em 1967 o IBGE se desvincula da Presidência.

A relação do IBGE com o poder central da República teve diferentes fases. Nos anos de 1934 e 1967, o Instituto esteve diretamente vinculado ao governo federal, e seus servidores eram regidos pelo funcionalismo público. Já entre 1967 e 1990, a empresa passou a contratar como iniciativa privada (Almeida, 2000). A vinculação hierárquica passou a fazer parte de um núcleo ministe- 
rial do governo, coordenada por um ministro de Estado. Entretanto no ano de 1990 o IBGE passa a ter um regime jurídico único tendo seus funcionários trabalhando novamente para o funcionalismo público federal. $\bigcirc$ autor expõe que em 2001 houve uma nova mudança de vinculação que transforma o IBGE em uma agência executiva do governo, porém com autonomia financeira.

Assim, Almeida (2000) aponta a importância da dissertação de mestrado do geógrafo Eli Alves Penha (1992), trabalho de Geografia Política que visa mostrar o enfoque do IBGE no contexto de centralização do Estado Novo.

Ainda para o autor, a importância do IBGE no campo da estatística era controlar as bases demográficas, de infraestrutura, emprego, renda e consumo, características que dariam suporte à elaboração de indicadores econômicos.

Constatando a configuração do IBGE e a importância que ele havia tomado no país devido aos dados estatísticos que produzia, a Geografia brasileira passa a reconhecer sua importância como ciência e a necessidade de contribuir com os estudos apresentados. Segundo Barcelos (2010), os estudos geográficos brasileiros até 1930, mesmo que dispersos estavam passando por um momento organizacional para tornarem-se científicos.

As reflexões de Machado (2005) esclarecem que, antes da institucionalização da Geografia, o período de 1870 a 1930 tem merecido menção de alguns autores que discutem a trajetória do pensamento geográfico no Brasil como Andrade (1977), Monteiro (1980), Becker (1985) e Dias (1989). Entretanto, para a autora os pesquisadores Caio Prado Júnior e Nelson Werneck Sodré seriam os mais qualificados para fazer uma análise contextual do pensamento geográfico no período. Um exemplo é obra de Sodré (1976) Introdução à geografia: geografia e ideologia, que critica o fato de a Geografia haver abandonou a História, tornando-se um instrumento de ideologias alienadas da realidade nacional.

Em suma, o texto de Machado (2005) aponta o contexto do pensamento geográfico nesse período de 1870 a 1930, quando assegura que o pensamento geográfico acabou sendo reduzido a uma dimensão descritiva e foi associado às teorias de aménagement do território. O aménagement citado pela autora é visto por Ficher (2003) como um conceito usado como "planejamento", "organização" ou "ordenamento do território" e ainda como uma implicação a uma dimensão política do território.

Toda essa reflexão em torno do pensamento geográfico e a temporalidade em que se encontrava, serviram como base para destacar a importância das publicações dos artigos científicos geográficos.

Seria indispensável o desenvolvimento do ensino e pesquisa na Geografia, somente assim, poderiam garantir condições concretas para realizar a interiorização do país e a extensão física do poder central. As publicações científicas como as monografias regionais, excursões científicas, possibilitariam um novo modelo de reconhecimento do território (Camargo, 2009).

Após compreender a configuração do pensamento geográfico e a importância da instauração do IBGE, pode-se apresentar a abertura que houve para as publicações dos trabalhos científicos realizados pela comunidade geográfica da época. No ano de 1939, surge a RBG conduzida pelo IBGE.

Nas argumentações de Camargo (2009), além de estimular a produção de novos conhecimentos especializados na área da Geografia, a fundação da RBG também poderia ser fundamental para outras funções. Assim, para o autor, essa produção intelectual contribuiria categoricamente para afirmar o grupo dos profissionais geógrafos(as) articulando-os ao CNG. 
No contexto histórico do surgimento da RBG e com noção da importância que a revista teria para os profissionais geógrafos(as) da época, é possível afirmar que a RBG serviu como um instrumento político para o reconhecimento das funções desempenhadas pelo profissional geógrafo(a).

Essa afirmação é confirmada pelas reflexões de Barcelos (2010), quando a autora destaca que o IBGE foi criado logo após os cursos superiores de Geografia nos estados de São Paulo (1934) e Rio de Janeiro (1935), contribuindo para que o CNG, antes formado majoritariamente por engenheiros, tivesse a participação de geógrafos(as), sendo Orlando Valverde o primeiro geógrafo contratado pelo CNG no ano de 1938.

Segundo Camargo (2009), a criação da Universidade do Brasill em 1937 demonstrava o esforço da profissionalização da Geografia do qual o governo Vargas (1930-1945) assumiu. Ainda para o autor, o governo estava assumindo a posição de manter uma organização nacional, e para isto seriam necessárias as informações do território existente.

Assim, a união entre um órgão de pesquisa mais uma instituição acadêmica, possibilitou a publicação dos artigos científicos permitindo dar visibilidade à produção do conhecimento científico geográfico brasileiro. Visto em Almeida (2000), é nesse contexto que o IBGE chama para sua lista de funcionários o alemão Leo Waibel, com seu vasto conhecimento em Geografia Agrária e que trabalhava com o processo de colonização sob pleito do governo federal. Ainda segundo o autor, outros nomes ganharam destaque nessa contribuição ao IBGE no início de sua funcionalidade, como Jean Tricart, Preston Everett James, Pierre Dansereau, Emmanuel de Martonne, entre outros.

Logo surge a necessidade de expandir a visibilidade dos trabalhos realizados pelos pesquisadores. A RBG, sendo essa uma publicação gestada pelo IBGE necessita da difusão e divulgação da produtividade científica geográfica brasileira que na época se concentrava apenas no Rio de Janeiro. Segundo Barcelos (2010), os objetivos centrais da revista eram divulgar o território nacional, publicar a metodologia geográfica moderna e a metodologia utilizada no ensino de Geografia e dos conhecimentos das ciências correspondentes e expor as ações da Geografia brasileira, em especial, os projetos do CNG.

A autora ainda afirma que inicialmente o periódico era trimestral e publicava em média cinco artigos por volume. A estrutura organizacional da revista contava com os seguintes tópicos: Artigos, Vultos da Geografia, Inquérito Geográfico, Comentário, Tipos e aspectos do Brasil, Atividades Geográficas, Noticiários, Relatórios, Resoluções, Leis e Bibliografia. Entretanto, em 1967, o IBGE reduziu a edição a artigos e noticiários e, a partir de 1975, outra modificação fez com que contasse com artigos e comentários.

Desse modo, levando em conta a importância da RBG, surgiram questionamentos referentes à visualização e ao acesso à produção científica da época, além da proporção de geógrafos(as) que teriam impulsionado a produção do conhecimento intelectual da Geografia brasileira.

Tendo a pesquisa como foco a produção do conhecimento científico, as relações de gênero e a produtividade da Geografia brasileira, se fez necessário a análise dos artigos publicados anteriormente ao surgimento dos periódicos on-line, ou no caso, a análise do primeiro periódico geográfico a RBG.

1 Em 1965, Universidade do Brasil passou a se chamar Universidade Federal do Rio de Janeiro (UFRJ, denominação que conserva até hoje. 
Para esta pesquisa, o universo de dados consiste em 222 edições do periódico disponíveis on-line, abrangendo o período de 1939 a 2005. ${ }^{2}$ Para comportar todos os artigos coletados e analisá-los quantitativamente, foi montado um Banco de Dados a partir do software livre LibreOffice, que possibilitou o armazenamento de variáveis (título do artigo, ano, nome do autor[es], sexo e procedência institucional, entre outras) de todos os artigos encontrados na RBG.

Nas 222 edições, foram publicados 723 artigos na RBG. Das análises, surgiu o apontamento de que a RBG contou com a participação de grandes nomes de geógrafos(as) brasileiros(as) que são e foram fundamentais para a construção da Geografia brasileira, como Aziz Nacib Ab'Saber (1955), ${ }^{3}$ Milton Santos (1956), 4 Speridião Faissol (1957), 5 Fany Davidovich (1963),6 Roberto Lobato Correa (1963), 7 Bertha Becker (1966)8 e Olga Maria Schild Becker (1975), 9 entre outros.

Para destacar o trabalho das pesquisadoras da época na RBG, a pesquisa evidencia que, dos 723 artigos coletados, apenas 228 foram escritos por mulheres, e algumas delas deram grande contribuição para o desenvolvimento da pesquisa na área da ciência geográfica: Fany Rachel Davidovich (13 artigos), Berta Koiffman Becker (12 artigos), Therezinha de Castro (9) artigos), Celeste Rodrigues Maio (8 artigos), Lysia Maria Cavalcanti Bernardes (8 artigos), Maria Francisca Theresa Cardoso (8 artigos) e Maria Novaes Pinto (6 artigos), lembrando que outras pesquisadoras também são autoras das publicações que compõem os 228, como Elza Coelho de Souza, Irene Garrido Filha, Olinda Vianna Mesquita (5 artigos), Adma Hamam de Figueiredo, Dora Rodrigues Hees (4 artigos), entre outras.

Os artigos abordados na revista foram diversos e discutiam sobretudo temas de geografia urbana, política, agrária, econômica, cartografia, geomorfologia, climatologia, industrial e assim por diante. Aponta-se novamente a importância da revista, devido a sua temporalidade e a construção do campo científico geográfico brasileiro.

Após a coleta dos dados e a busca dos autores fundamentais na produção do conhecimento científico geográfico brasileiro sobre os temas mais abordados na época, instiga-se a investigação pela produtividade relativa a homens e mulheres. Com a ajuda da ferramenta do software livre LibreOffice, filtraram-se os dados com o recorte central na produção de artigos por gênero. $\bigcirc$ Gráfico 1 expressa a distribuição temporal do número de artigos publicados por homens e mulheres:

2 No segundo semestre de 2016, a revista foi reativada, mas esta pesquisa se atém aos anos entre 1939 e 2005.

3 Primeiro artigo publicado na RBG: "Contribuição à geomorfologia do litoral paulista" (1955).

4 Primeiro artigo publicado na RBG: "A cidade de Jequié e sua região" (1956).

5 Primeiro artigo publicado na RBG: "O problema do desenvolvimento agrícola do sudeste do Planalto Central do Brasil" (1957).

6 1Primeiro artigo publicado na RBG: "Estudos para a geografia das indústrias do Brasil Sudeste" (1963).

7 Primeiro artigo publicado na RBG: "Regime de exploração da terra no Nordeste, uma tentativa da expressão cartográfica" (1963).

8 Primeiro artigo publicado na RBG: "Expansão do mercado urbano e transformação da economia pastoril" (1966).

9 Primeiro artigo publicado na RBG: "Proposição metodológica para análise dos diferenciais entre imigrantes e nativos nas áreas metropolitanas do Sudeste" (1975). 


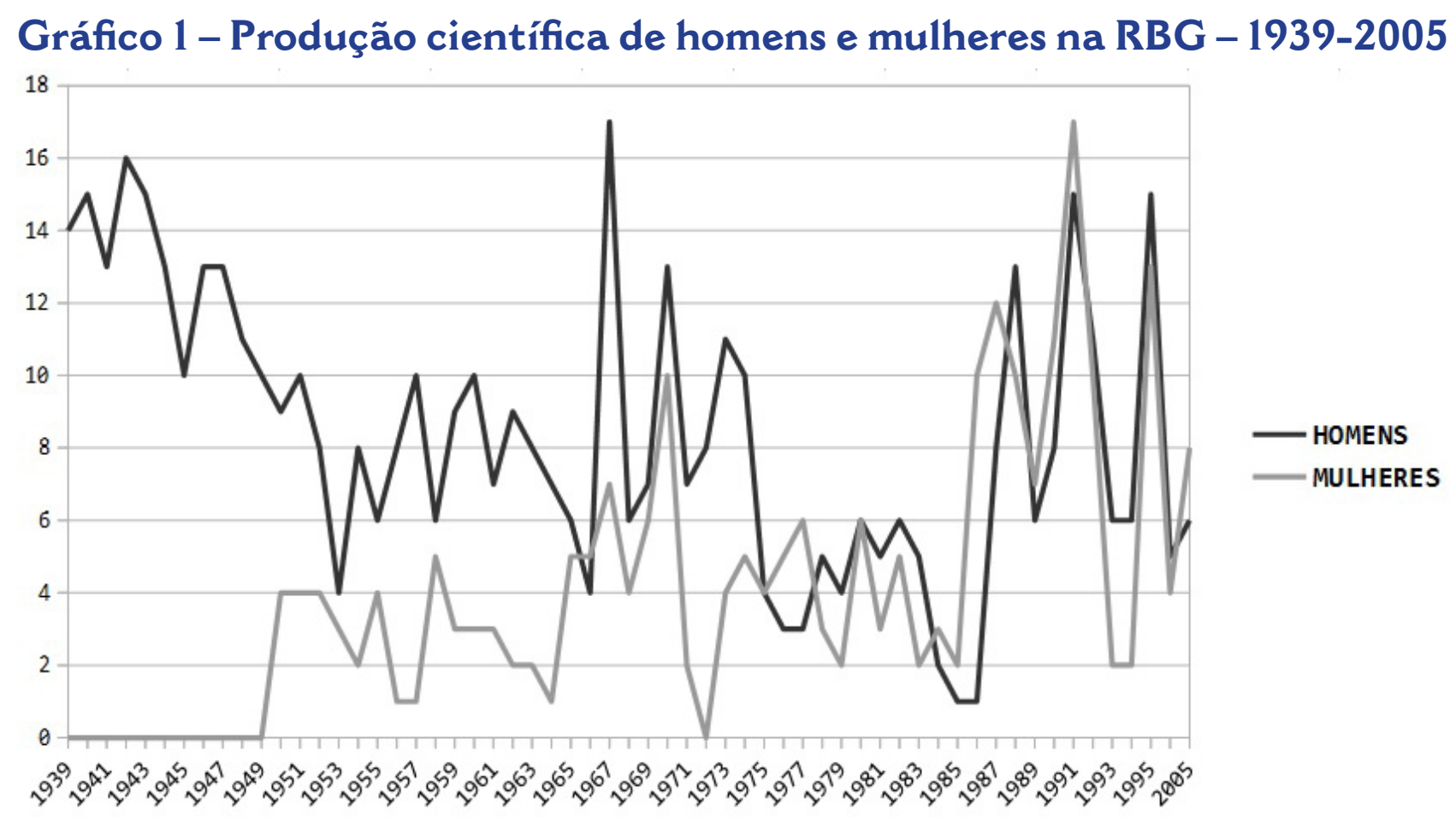

fonte: Revista Brasileira de Geografia. organização: Os autores.

Um primeiro aspecto que merece destaque no Gráfico 1 é o fato de que, só em 1950, mais de uma década depois da criação da RBG, são publicados os primeiros artigos em primeira autoria por parte das mulheres. Assim, a supremacia masculina nos anos iniciais é ampla, característica que se manteve até os anos 1970. Daí em diante ocorre, paulatinamente, diminui a grave discrepância entre a produção científica de homens e mulheres no periódico.

Curiosamente, é nessa mesma conjuntura da década de 1970 que nascem os primeiros cursos de pós-graduação no país sendo inaugurais no campo geográfico os dois programas, Geografia Física e Geografia Humana, criados em 1971 na Universidade de São Paulo (USP). Na sequência, ainda seriam implementados na área da Geografia os Programas de Pós-Graduação da Universidade Federal do Rio de Janeiro (UFRJ), em 1972, da Universidade Federal de Pernambuco (UFPE), em 1976, e da Universidade Estadual Paulista, campus de Rio Claro (UNESP-RC), em 1977. A implementação de novos cursos na área apresenta relativo aumento nas décadas seguintes, com uma dinâmica mais frequente de debates e reinvindicações entre os pesquisadores, expressa em 1993 com a fundação da Associação Nacional de Pós-graduação e Pesquisa em Geografia (Anpege). Este progressivo aumento e demanda de programas stricto sensu adquire maior respaldo com a obtenção de licença de afastamento para a realização de cursos de pós-graduação, liberando docentes de suas atividades departamentais, de aula e pesquisa. Bem como, é atrelada a isto a política de concessão de bolsas por agências de fomento (Borzacchiello da Silva; Dantas, 2005). Sendo que a partir dos anos 2000 acontece uma intensificação deste processo derivado de maiores investimentos governamentais visando aumentar a mão de obra qualificada (majoritariamente mestres e doutores) e mitigar assimetrias regionais (distribuir mais cursos no interior do país) (Sant'Anna Neto, 2012). 
A produção de artigos está diretamente vinculada aos recursos humanos dos programas de pós-graduação, uma vez que é nessa modalidade que a pesquisa é fomentada e desenvolvida. Desse modo, existe um forte indicativo de que a maior participação feminina no contexto da produção científica, sendo uma amostra desse fenômeno a emblemática e tradicional RBG, se relaciona com o aumento e difusão dos espaços de pesquisa em Geografia pelo Brasil em decorrência das políticas supracitadas. Pois, tal como demonstrou a investigação de Cesar (2015), a diferença entre o contingente de homens e mulheres é menor e, em alguns casos, até inversa (valores negativos), nos cursos mais recentes, majoritariamente implementados nas regiões Norte, Nordeste e Centro-Oeste do país (Tabela 1).

\section{Tabela 1 - Gap de representatividade de homens e mulheres entre docentes e discentes de pós-graduação em geografia no Brasil - percentual por região}

\begin{tabular}{lccccc}
\hline & NORTE & NORDESTE & CENTRO-OESTE & SUDESTE & SUL \\
\hline Docentes & 2,2 & 1,5 & 2,2 & 9,6 & 5,1 \\
\hline Disc. Doutorado & 0 & $-0,74$ & 0,79 & 8,88 & 1,18 \\
\hline Disc. Mestrado & $-0,43$ & 0,34 & 0,27 & $-1,37$ & 2,75 \\
\hline & & & & & $\begin{array}{r}\text { fonte: Cesar (2015). } \\
\text { organização: Os autores. }\end{array}$
\end{tabular}

Contudo, mesmo com esta configuração apresentada, é necessário ressaltar que as muIheres para conseguirem permanecer na carreira científica e serem bem-sucedidas profissionalmente, precisam estabelecer sua identidade profissional em harmonia com o modelo masculino, envolvendo seus compromissos em tempo integral com e para o trabalho científico, nas relações de competitividade e produção (Velho, 2006). Nessa configuração, encontra-se a produtividade científica, que é calculada pelo número de publicações em artigos e livros.

O campo científico geográfico, assim como os outros campos do conhecimento científico, mostra-se um ambiente masculinizado e composto por apenas uma visão de mundo. Essa mesma reflexão pode ser confirmada pelas ideias de Narvaz e Koller (2006), que argumentam sobre a necessidade de se reconhecerem diferenças entre os universos masculino e feminino.

Assim, reconhecendo as diferenças presentes nos universos citados, a pesquisa alerta para a importância de se compreender o processo histórico e social que ambos vêm seguindo. Esse seguimento de publicações se refletirá no que diz Morin (1996) sobre a produção do conhecimento científico ser carregada de um processo sociocultural e histórico da comunidade científica.

\section{Considerações finais}

Com base nas reflexões apresentadas, este texto ressaltou que, embora sejam invisibilizadas na produção científica, é fundamental entender as relações de gênero para promover um ambiente equânime em termos de oportunidades e de valorização entre homens e mulheres no espaço acadêmico. Entendida como forma hegemônica de conhecimento, a ciência é produzida por pessoas que trazem suas marcas do tempo e do espaço, bem como suas características pessoais. A partir da análise do contexto histórico do campo científico geográfico no Brasil 
pela publicação de artigos na paradigmática RBG, se constata o predomínio de pesquisadores homens na produção desde o final dos anos 1930. Só com a política de expansão e a interiorização dos cursos de pós-graduação em Geografia pelo país, iniciada nos anos 1970, diminui paulatinamente a disparidade de produção entre os gêneros. Contudo, concomitantemente a crescente participação feminina no âmbito da veiculação científica, persistem no universo acadêmico o imaginário de supressão da subjetividade e da pluralidade e o domínio simbólico do secular sujeito homem, neutro e racional.

\section{Referências}

ALMEIDA, R. S. A geografia e os geógrafos do IBGE no período 1938-1998: uma relação entre documento e memória. Tese (Doutorado em Geografia) - Universidade Federal do Rio de Janeiro, Rio de Janeiro, 2000.

ANDRADE, M. C. O pensamento geográfico e a realidade brasileira. Boletim Paulista de Geografia, São Paulo, n. 54, p. 5-39, jun. 1977.

ANDRÉ, I. M. O gênero em geografia: introdução de um novo tema. Finisterra, Lisboa, n. XX V, p. 331-348, 1990.

BARCELOS, S. S. M. A geografia urbana na Revista Brasileira de Geografia (1939-1995). Dissertação (Mestrado em Geografia) - Universidade Estadual do Rio de Janeiro, Rio de Janeiro, 2010.

BECKER, B. K. Fronteira e urbanização repensadas. Revista Brasileira de Geografia, v. 47, n. 3, p. 357-371, 1985.

BORZACCHIELLO DA SILVA, J.; DANTAS, E. W. C. A pós-graduação em geografia no Brasil: uma contribuição à política de avaliação. Revista da Anpege, v. 2, n. 2, p. 21-37, 2005.

BOURDIEU, P. Os usos sociais da ciência: por uma sociologia clínica do campo científico. São Paulo: Unesp, 2004.

CAMARGO, A. P. R. A Revista Brasileira de Geografia e a organização do campo geográfico no Brasil (1939-1980). Revista Brasileira de História da Ciência, Rio de Janeiro, v. 2, n. 1, p. 23-39, 2009.

CESAR, T. R. A. O. C. Gênero, poder e produção científica geográfica no

Brasil de 1974 a 2013. Dissertação (Mestrado em Gestão do Território) - Universidade Estadual de Ponta Grossa, Ponta Grossa, 2015.

DIAS, L. C. D. La pensée géographique au Brésil: hier et aujourd冈hui. L囚Espace Géographique, v. XVII, n. 3, p. 193-203, 1989.

FICHER, A. A dimensão espacial no "aménagement" do território: o exemplo Francês. Ra'ega, Curitiba, v. 7, p. 9-17, 2003.

FOUCAULT, M. História da sexualidade I: a vontade de saber. Rio de Janeiro: Graal, 1988.

FOUREZ, G. A construção das ciências: introdução à filosofia e à ética das ciências. São Paulo: Ed. Unesp, 1995. 
GARCÍA-RAMÓN, M. D. Women and Geography in Spanish Universities. Professional Geographer, Didcot, v. 40, n. 3, p. 307-345, 1988.

; ORTIZ, A.; PUJOL H. Universidade e gênero na Espanha: trajetórias acadêmicas de docentes na geografia. In: SILVA, J. M.; ORNAT, M. J.; CHIMIN JUNIOR, A. B. Espaço, gênero e feminilidades ibero-americanas. Ponta Grossa: Todapalavra, 2011. p. $43-63$.

IBGE. INSTITUTO BRASILEIRO DE GEOGRAFIA E ESTATÍSTICA. A Era Vargas: dos anos 20 a 1945. CPDOC-FGV - Centro de Pesquisa e Documentação de História Contemporânea do Brasil, Rio de Janeiro/São Paulo, [s.d.]. Disponível em: http://cpdoc.fgv.br/producao/dossies/AEraVargas1/anos37-45/PoliticaAdministracao/IBGE. Acesso em: 11 set. 2018.

MACHADO, L. O. Origens do pensamento geográfico no Brasil: meio tropical, espaços vazios e a idéia de ordem (1870-1930). In: CASTRO, I. E.; GOMES, P. C. C.; CORREA, R. L. Geografia: conceitos e temas. Rio de Janeiro: Bertrand Brasil, 2005. p. 309-352.

McDOWELL, L. Gender, identity and place: understanding feminist geographies. Minneapolis: University of Minnesota Press, 1999.

; PEAKE, L. Women in British geography revisited: or the same old story. Journal of Geography in Higher Education, Didcot, v. 14, n. 1, p. 19-30, 1990.

MONK, J.; HANSON, S. On Not Excluding Half of the Human in Human Geography. The Professional Geographer, v. 34, n. 1, p. 11-23, 1982.

MONTEIRO, C. A. F. A geografia no Brasil: 1934-1977: avaliação e tendências. São Paulo: Instituto de Geografia da Universidade de São Paulo, 1980.

MORIN, E. O problema epistemológico da complexidade. Lisboa: EuropaAmérica, 1996.

NARVAZ, M. G.; KOLLER, S. H. Metodologias feministas e estudos de gênero: articulando pesquisa, clínica e política. Psicologia em Estudo, Maringá, v. 11, n. 3, p. 647-654, 2006.

PENHA, E. A. A criação do IBGE no contexto da centralização política do Estado Novo. Dissertação (Mestrado em Geografia Política) - Universidade Federal do Rio de Janeiro, Rio de Janeiro, 1992. Disponível em: http://biblioteca.ibge.gov.br/visualizacao/monografias/GEBIS\%20-\%20RJ/ColecaoMemorialnstitucional/04 A\%20Criacao\%20do\%20 IBGE.pdf. Acesso em: 11 set. 2018.

RBG. REVISTA BRASILEIRA DE GEOGRAFIA. Disponivel em: http://www.grupogeobrasil.com.br/maisinfo.php?id=revista. Acesso em: 11 set. 2018.

RIBEIRO, A. L. Razão e sensibilidade: a desconstrução do mito da fragilidade feminina. In: CONGRESSO DE TEOLOGIA DA PUC-PR, 10., 2011, Curitiba. Anais eletrônicos... Curitiba: Champagnat, 2011. p. 477-488.

ROSE, G. Progress in geography and gender: or something else. Progress in Human Geography, Didcot, v. 17, n. 4, p. 531-537, 1993.

SANT' ANNA NETO, J. L. Os desafios da pesquisa e pós-graduação em geografia no Brasil. Revista Discente Expressões Geográficas, Florianópolis, v. VIII, n. 8, p. 14-28, ago. 2012. 
SILVA, J. M. Geografias subversivas: discursos sobre espaço, gênero e sexualidades. Ponta Grossa: Todapalavra, 2009.

SILVA, J.; CESAR, T. R. A. O.; PINTO, V. A. M. Gênero e geografia brasileira: uma análise sobre o tensionamento de um campo de saber. Revista da Anpege, v. 11, n. 15, p. 185-200, jan./jun. 2015.

SODRÉ, N. W. Introdução à geografia: geografia e ideologia. Petrópolis, RJ: Vozes, 1976.

SOUSA SANTOS, B.; MENESES, M. P.; ARRISCADO, J. N. Introdução: para ampliar o cânone da ciência- a diversidade epistemológica do mundo. In: SOUSA SANTOS, B. Semear outras soluções: os caminhos da biodiversidade e dos conhecimentos rivais. Rio de Janeiro: Civilização Brasileira, 2005.

VELHO, L. Prefácio. In: SANTOS, L. W.; ICHIKAWA, E. Y.; CARGANO, D. F. (Org.) Ciência, tecnologia e gênero: desvelando o feminino na construção do conhecimento. Londrina: lapar, 2006. p. xiii-xviii. 